\title{
Behavior of Large-Scale Rectangular Columns Confined with FRP
}

\section{Composites}

\author{
H. Toutanji ${ }^{\mathrm{a}}$, M. Han ${ }^{\mathrm{a}}$, J. Gilbert ${ }^{\mathrm{b}}$ and S. Matthys ${ }^{\mathrm{c}}$ \\ ${ }^{a}$ Dept. of Civil and Env. Eng., University of Alabama in Huntsville, Huntsville, AL 35805, USA \\ ${ }^{b}$ Dept. of Mechanical and Aerospace Eng., University of Alabama in Huntsville, Huntsville, AL \\ 35805, USA \\ ${ }^{c}$ Dept. of Structure Eng., Ghent University, Technologiepark-Zwijnaarde 9, B-9052, Gent, \\ Belgium
}

\begin{abstract}
This paper focuses on axially loaded, large-scale rectangular reinforced concrete (RC) columns confined with fiber reinforced polymer (FRP) wrapping. Experimental tests are conducted to obtain the stress-strain response and ultimate load for three field size columns having different aspect ratios and/or corner radii. Effective transverse FRP failure strain and the effect of increasing confining action on the stress-strain behavior are examined. Existing strength models, the majority of which were developed for small-scale specimens, are applied to predict the structural response. Since some of them fail to adequately characterize the test data and others are complex and require significant calculation, a simple design-oriented model is developed. The new model is based on the confinement effectiveness coefficient, an aspect ratio coefficient, and a corner radius coefficient. It accurately predicts the axial ultimate strength of the large-scale columns at hand and, when applied to the small-scale columns studied by other investigators, produces reasonable results.
\end{abstract}


Keywords: FRP; rectangular column; large-scale; axial strength; axial and lateral strain; stress-strain response

\section{INTRODUCTION}

Confinement of concrete is an efficient technique to increase the load-carrying capacity and ductility of RC concrete columns. Under the lateral confining pressure provided by the confinement material, the concrete column is subjected to a tri-axial stress state, thereby increasing the ultimate stress and strain.

Lateral confining action was initially accomplished by restraining the lateral expansion of concrete columns with closely spaced steel stirrups. Since then, techniques have been developed to upgrade and confine structures by means of FRP wrapping, independently, or in combination with steel stirrups.

Investigators determined that the rectangular sections laterally confined using FRP were not as effective as their circular counterparts. This was attributed to the higher stress concentration found at the corners and the non-uniformity in confinement (Chaallal and Shahawy 2000). Rounding a column's corners has now become commonplace because it helps to reduce the cutting edge effect on the confining sheets.

One early model used to predict the axial strength of rectangular columns was developed by the International Conference of Building Officials (ICBO 1997). This model predicts the ultimate axial strength of confined columns $\left(\dot{f}_{c c}\right)$ and the ultimate axial strength of unconfined columns $\left(f_{c o}\right)$ for rectangular columns with aspect ratios $(b / d)$ less than 1.5 . Although other models have been developed to predict the axial strength behavior of rectangular columns, the effects of aspect ratio and section size on the ultimate load and stress-strain behavior have received limited attention. Moreover, the majority of specimens tested to verify these models are relatively small 
with cross sectional dimensions $(d, b): d=94 \mathrm{~mm}$ (3.7in.), $108 \mathrm{~mm}$ (4.25in.), $150 \mathrm{~mm}$ (5.91 in.), $152 \mathrm{~mm}$ (5.98in.), and $b=108 \mathrm{~mm}$ (4.25in.), $150 \mathrm{~mm}$ (5.91in.), $152 \mathrm{~mm}$ (5.98in.), $188 \mathrm{~mm}$ (7.4in.), $203 \mathrm{~mm}$ (7.99in.) (Lam and Teng 2003). It is therefore uncertain whether the existing models developed to predict the axial strength characteristics of small-scale rectangular columns can be applied to accurately characterize the behavior of their large-scale counterparts.

The current study focuses on two larger field-size columns $355 \times 355 \mathrm{~mm}$ (14x14in.) columns with different radii, and one $250 \times 500 \mathrm{~mm}$ (10x20in.) column having the same radii as one of the square samples confined with external FRP wrapping reinforcement. As far as the authors' knowledge, these samples have the biggest size of all specimens tested by previous studies (Wang and Restrepo 2001). The number of samples was limited due to the difficulty in testing these larger structures, but the selections allow the effects of varying the aspect ratio $(b / d)$, fiber thickness, and corner radius to be examined. The effect of increasing confining strength and the effective transverse FRP failure strain (defined as the transverse FRP strain at ultimate load $\varepsilon_{c l u}$ over the FRP failure strain $\left.\varepsilon_{\text {fum }}\right)$ were also investigated.

\section{RESEARCH SIGNIFICANCE}

This paper provides an evaluation of the previously published models that predict the ultimate axial strength and the entire stress-strain response of FRP-confined concrete and assess their reliability against the results obtained from large-scale columns. The effect of confinement on the ultimate failure strain of the FRP composite sheets is quantified. This paper should provide a better understanding of the behavior of fiber-wrapped or FRP confined rectangular concrete columns. The results presented in this paper should be used to predict the ultimate strength of actual-size columns in the current retrofitting projects in the field. 


\section{EXPERIMENTAL PROCEDURE}

\section{Test Specimens and Material Properties}

This study concentrates on non-circular columns, and is a part of a previous study done by Matthys et al. $(2005,2006)$. The three large-scale RC rectangular columns described herein are referred to as $\mathrm{K} 9, \mathrm{~K} 10$, and $\mathrm{K} 11$; columns $\mathrm{K} 1$ though $\mathrm{K} 8$ were circular with results reported elsewhere (Matthys et al. 2006), and column K1 was unwrapped. Schematic diagrams of the confined columns along with their wrapping configuration are shown in Figure. 1. Each column has a total length of $2 m(6 \mathrm{ft}-7 \mathrm{in}$.), a longitudinal steel reinforcement ratio of approximately $0.98 \%$, and $8 \mathrm{~mm}$ (0.31in.) diameter stirrups spaced every $140 \mathrm{~mm}$ (5.51in.). An extra stirrup reinforcement is included at the columns' ends. Columns K9 and K10 are square; K11 is rectangular. All three have approximately the same cross sectional area, $A_{g}=125,000 \mathrm{~mm}^{2}$ $\left(193.75 \mathrm{in}^{2}\right)$

The concrete used to construct the columns has a mean compressive strength at 28 days of $38.2 \mathrm{MPa}(5.5 \mathrm{ksi})$. The corners of the columns are rounded with radii of $30 \mathrm{~mm}(1.18 \mathrm{in}$.) (K9 and K11) and $15 \mathrm{~mm}(0.59 \mathrm{in}).(\mathrm{K} 10)$.

CFRP (graphite) fabrics are used to confine the specimens. The 'wet lay-up' FRP type reinforcement is impregnated and cured in-situ. The CFRP consists of a SyncoTape system, comprised of quasi unidirectional fabric, TU600/25 $\left(600 \mathrm{~g} / \mathrm{m}^{2}\left(0.1229 \mathrm{lb} / \mathrm{ft}^{2}\right)\right.$ fibers in the main direction and $25 \mathrm{~g} / \mathrm{m}^{2}\left(0.0051 \mathrm{lb} / \mathrm{ft}^{2}\right)$ in perpendicular direction), and PC 5800 epoxy. The fabric has a width of $200 \mathrm{~mm}(7.87 \mathrm{in}$.) and a nominal thickness of $0.300 \mathrm{~mm}(0.0118 \mathrm{in}$.). The PC 5800 is a solvent-free 2-component epoxy primer consisting of a resin (Component A) and a hardener (Component B). The test parameters of the wrapped columns and the properties of the reinforcement are given in Tables 1 and 2, respectively. 


\section{Specimen Preparation and Test Procedure}

Test specimens and concrete quality control specimens were cast in the laboratory. The formwork was removed after 1 day. Concrete curing took place under plastic foil during the first 7 days and under laboratory conditions thereafter. Once the concrete columns were fully cured, they were wrapped with FRP, following the manufacturer's recommendations outlined in the next paragraph.

Before the FRP was applied, the concrete surface was cleaned. The epoxy was prepared by mixing 3 volumetric parts of component A (the resin) with 1 part of component B (the hardener). This compound was deposited liberally on both surfaces of contact by using a paintbrush. A uniform tensile force was applied to the fiber during application to ensure a tight wrap. Since the tensile force was applied by hands, this force was kept as uniform as possible. Air was forced out of the bonding layer using a customized roller. The FRP was applied a minimum of 7 and a maximum of 9 days prior to the time that the columns were tested.

Each column was tested to failure in a displacement control mode; load was applied at a rate of $0.5 \mathrm{~mm} / \mathrm{min}$. The axial and transverse deformations of the columns were measured both manually and electronically. Manual measurement relied on dial gauges having a gauge length of $1 \mathrm{~m}(3.28 \mathrm{ft})$ and mechanical extensometers with gauge lengths of $200 \mathrm{~mm}$ (7.87in.) or $50 \mathrm{~mm}$ (1.97in.). Electronic measurements relied on strain gauges on the stirrups (with gauge lengths of $200 \mathrm{~mm}(7.87 \mathrm{in}$.) or $80 \mathrm{~mm}(3.15 \mathrm{in})$.$) and strain gauges on the vertical rebars.$

\section{TEST RESULTS}

\section{Behavior at Ultimate Load}

Table 3 shows test results including the maximum load, $Q_{\max }$, the maximum stress, $Q_{\max } / A_{g}$, and the strength increase, $Q_{\max } / Q_{r e f}$, where $Q_{r e f}$ is the maximum load of unwrapped circular column 
K1. Other quantities documented there include the axial $\left(\varepsilon_{c l}\right.$ and $\left.\varepsilon_{c u}\right)$ and transverse strains $\left(\varepsilon_{c l l}\right.$ and $\varepsilon_{c l u}$ ) at maximum and ultimate load, respectively. The last column lists the effective FRP strain coefficient, $\left(\beta=\varepsilon_{c l u} / \varepsilon_{f u m}\right)$, defined as the ratio of the transverse failure strain $\varepsilon_{c l u}$ to the ultimate FRP tensile strain $\varepsilon_{f u m}$. In all cases, the strains are the mean values taken from the strain gauge measurements.

Figure 2 shows how the FRP reinforcement failed on the confined concrete columns that had square cross sections but different radii. In both cases, the FRP reinforcement fractured just beside one, or more, of the rounded corners. At ultimate load, when the confinement action was no longer provided due to FRP fracture, the internal steel started to buckle and the crushed concrete fell down between the fractured FRP. A similar trend was observed on the third column that had the rectangular section.

\section{Stress-Strain Behavior and Effectiveness of Wrapping Configuration}

Figure 3 shows two sets of stress-strain curves generated while testing the columns. Both are based on the axial stress; one set corresponds to the axial strain, the other to the transverse strain. The square column with the larger corner radii (K9) has a strength increase of 1.12 (see Column 3, Table 3) compared to the strength increase of 1.09 in the square column with the smaller corner radii. Even though the rectangular column (K12) has the same corner radii as $\mathrm{K}$, it has the smallest strength increase of all (1.07).

Figure 4 (ACI Committee 440 Report 2002) illustrates that the confining action occurs predominately at the rounded corners. Unlike a circular section, for which the concrete core is fully confined; for a square or rectangular section wrapped with FRP and with corners rounded with a radius, a parabolic arching action is assumed for the concrete core where full confinement is developed, which is indicating that the process of wrapping of rectangular sections becomes 
more efficient when the corner radii are larger with corners situated closer together. Significantly higher strength increases, ranging from 1.70 to 1.80 , have been observed by researchers while testing circular confined columns under axial loading (Matthys et al. 2005). Thus, it may be concluded that, for square or rectangular sections, the wrapping becomes more efficient as the cross section approaches a circular section (ACI Committee 440 Report 2002, Matthys et al. 2005 and 2006).

\section{Behavior at Ultimate Strain and Effective FRP Strain Coefficient}

According to the experimental results obtained by Matthys et al. (2006), the effective FRP strain coefficient (the ratio of circumferential ultimate strain to ultimate strain of the FRP composite) for fully wrapped circular columns ranged from 0.55 to 0.62 . The results listed in the last column of Table 3 reveal that this quantity is much smaller for rectangular columns.

Because of the knife-effect, the smaller the radii are around the corner, the smaller the ultimate circumferential strain, and the smaller the effective FRP strain coefficient will get for the same composite material that has stable tensile stress. The substantial decrease in this coefficient for non-circular sections is attributed to the stress concentration and inhomogeneous strain that occur in the corners of the column. It has been noted that these effects can be reduced by rounding the corners; or, by locally strengthening them with strips of reinforcement prior to continuous wrapping (Campione et al. 2004). The researchers cited preferred the first approach, since it reduced the risk of fiber failure at the corners and increased the equivalent confinement pressure (Campione et al. 2006).

Referring to the axes labeled on Figure 4, the maximum lateral (transverse) confinement pressures $\left(f_{l u}\right.$ and $\left.f_{l y}\right)$ are (Matthys 1999): 


$$
f_{l u x}=k_{c o n f x} \varepsilon_{\text {fum }}=k_{\text {confx }} \times \frac{\varepsilon_{c l u}}{\beta}=k_{c o n f x}^{\prime} \times \varepsilon_{c h t}
$$

where $k_{\text {confix }}=\rho_{f k} k_{e} E_{f}$ and $k_{\text {confix }}^{\prime}=k_{\text {confex }} / \beta$

and

$$
f_{\text {luy }}=k_{\text {confy } y} \varepsilon_{\text {fum }}=k_{\text {confy }} \times \frac{\varepsilon_{c l u}}{\beta}=k_{c o n f y}^{\prime} \times \varepsilon_{c l u}
$$

where $k_{\text {confy }}=\rho_{f y} k_{e} E_{f}$ and $k_{\text {confy }}^{\prime}=k_{\text {confy }} / \beta$.

As mentioned previously, the quantity, $\beta$, is referred to as the effective FRP strain coefficient $\left(\beta=\varepsilon_{c l u} / \varepsilon_{f u m}\right)$, defined as the ratio of the transverse failure strain $\varepsilon_{c l u}$ to the ultimate FRP tensile strain $\varepsilon_{f u m}$.

The ratios $\rho_{f x}$ and $\rho_{f y}$ reflect the amount of transverse confining reinforcement in the $\mathrm{x}$ and $\mathrm{y}$ directions, respectively. These quantities can be expressed as

$$
\begin{gathered}
\rho_{f x}=\frac{2 b_{f} t_{j}}{s d} \\
\rho_{f y}=\frac{2 b_{f} t_{j}}{s b}
\end{gathered}
$$

where $b_{f}$ is the width of the FRP, $t_{j}$ is the FRP thickness (total thickness in case of multiple layers), and $s$ is the center to center spacing of the FRP ( $s=b_{f}$ for fully wrapped columns). $b$ and $d$ are longer and shorter sides of rectangular section, respectively.

The confinement effectiveness confinement, $k_{e}$, is given by

$$
k_{e}=\frac{A_{e}}{A_{c}}=1-\frac{b^{\prime 2}+d^{\prime 2}}{3 A_{g}\left(1-\rho_{s g}\right)}
$$

where $A_{g}$ is the gross cross sectional area; and, $\rho_{s g}$ is the reinforcement ratio of the longitudinal steel reinforcement with respect to the gross cross sectional area $\left(\rho_{s g}=A_{s} / A_{g}\right) . b^{\prime}=b-2 r, d^{\prime}=d-2 r$, and $r$ is corner radius. 
Another parameter of interest is the confining stiffness defined as (Matthys et al. 2005):

$$
k_{\text {conf }}=\frac{2 t_{j} E_{f}}{D} \varepsilon_{c l u}
$$

where $\varepsilon_{c l u}=\beta \varepsilon_{\text {fum }}$

and

$$
D=\frac{2 b d}{(b+d)}
$$

\section{Stress-Strain Response Models}

Figures 5-7 show the stress-strain plots obtained for the large-scale columns K9, K10, and K11, respectively. The data are plotted along with behavior predicted by four models developed by Lam and Teng (2003), Chaallal et al. (2003), Youssef (2004), and Harajli et al. (2006).

The three models developed by Lam and Teng, Youssef, and Harajli et al. all predicted the stress-strain behavior quite well. The stress-strain model developed by Chaallal et al assumes a tri-linear stress-strain curve and does not provide a very good representation of the experimental data especially at higher stress/strain levels.

As far as strength is concerned, the model developed by Lam and Teng predicted the maximum stress point and the corresponding axial strain reasonably well whereas both Youssef's model and the model developed by Harajli et al. predicted a lower maximum axial stress than obtained experimentally. Moreover, Youssef's model did not predict the stress-strain curves after the transition point (when the axial strain exceeded $0.002 \mathrm{~mm} / \mathrm{mm}$ ) and this model significantly overestimated the ultimate axial strain in the columns.

Although the overall stress-strain behavior is important, the accurate prediction of strength is critical to the design process. As discussed next, many other models have been developed to pinpoint this parameter in rectangular columns confined with FRP. But these models were all 
verified with small-scale specimens and, as the results of predicted-to-test ultimate load ratios shown in Table 4, may not provide accurate results when applied to the large-scale columns described herein.

\section{EXISTING CONFINING MODELS FOR RECTANGULAR SECTION COLUMNS}

\section{ACI Committee 440 (ACI 440.2R 2002)}

This model predicts the compressive strength $\left(f_{c c}\right)$ and ultimate axial strain $\left(\varepsilon_{c u}\right)$ for FRP-confined rectangular concrete columns based on the arching action associated with rectangular FRP-confined concrete. A shape factor $k_{e}$ is introduced that corresponds to the confinement effectiveness coefficient defined in Eq. 5.

The compressive strength of the confined concrete is predicted by an equation, originally proposed by Mander et al (1988) for steel-confined concrete, as:

$$
f_{c c}^{\prime}=f_{c o}^{\prime}\left(2.254 \sqrt{1+7.94 f_{l}^{\prime} / f_{c o}^{\prime}}-2 f_{l}^{\prime} / f_{c o}^{\prime}-1.254\right)
$$

where $f_{l}^{\prime}$ is the effective lateral confining pressure:

$$
f_{l}^{\prime}=k_{e} f_{l}
$$

In the above equation, $f_{l}$ is an equivalent confining pressure given by:

$$
f_{l}=\frac{2 \sigma_{j} t_{j}}{D}=\frac{2 E_{f} \varepsilon_{c l u} t_{j}}{D}
$$

where $D$ is the equivalent diameter of rectangular cross section, defined by Eq. 8; $\varepsilon_{c l u}=0.004<0.75 \varepsilon_{\text {fum }}$. The ultimate axial strain $\varepsilon_{c u}$ is:

$$
\varepsilon_{c u}=\frac{1.71\left(5 f_{c c}^{\prime}-4 f_{c o}^{\prime}\right)}{E_{c}}
$$

where $E_{c}$ is given by 


$$
E_{c}=4730 \sqrt{f_{c o}^{\prime}} .
$$

\section{Mirmiran and Shahawy (1997)}

In this model, the shape factor $k_{e}$ is defined as:

$$
k_{e}=\frac{2 r}{D}
$$

where $D$ is still the equivalent diameter of rectangular cross section, and defined as the length of the longest side of the rectangular section. The compressive strength is:

$$
f_{c c}^{\prime}=f_{c o}^{\prime}+k_{1} f_{l}^{\prime}
$$

where the effective lateral confining pressure, $f_{l}(\mathrm{Eq} .10)$, is a function of the shape factor $k_{e}$ and the equivalent confining pressure, $f_{l}$. The confinement effectiveness coefficient, $k_{l}$, is defined as:

$$
k_{1}=6.0 f_{l}^{-0.3}
$$

\section{Campione and Miraglia (2003)}

This model was developed exclusively for square columns with width, $b$, having rounded corners of radius, $r$. The nominal hoop rupture stress in the FRP jacket, $\sigma_{j}$, is:

$$
\sigma_{j}=f_{f f p}\left[\left(1-\frac{\sqrt{2}}{2} k_{i}\right) \frac{2 r}{b}+k_{i} \frac{\sqrt{2}}{2}\right]
$$

where the $k_{i}$ is a stress reduction factor determined by regression analysis. The lateral confining pressure is defined in terms of the FRP thickness, $t_{j}$, by:

$$
f_{l}=\frac{2 \sigma_{j} t_{j}}{b}
$$




\section{Chaallal et al. (2003)}

This model suggests a tri-linear stress-strain response consisting of three successive regions. The first region depicts linear elastic behavior similar to that associated with unconfined concrete. Very little concrete expansion occurs within this region. The second region is a transition zone that begins when micro-cracking first occurs due to the confining pressure created by the FRP wrapping. The third region reflects the point at which extensive cracking occurs in the concrete core. The slope of the curve that characterizes this region is highly dependent on the FRP stiffness.

The ultimate compressive strength of the confined concrete is given by:

$$
f_{c c}^{\prime}=f_{c o}^{\prime}+4.12 \times 10^{5} k
$$

where the stiffness coefficient, $k$, is given in terms of the cross sectional area of the concrete; and, the elastic modulus of the fiber and concrete as:

$$
k=\frac{E_{f} \times A_{f}}{E_{c} \times A_{c}} .
$$

The term $A_{f}$ is the area of an inch-wide FRP sheet ( $A_{f}=$ thickness x $1 \mathrm{in}$.). The ultimate axial strain of the confined concrete $\left(\varepsilon_{c c}\right)$ is predicted by:

$$
\varepsilon_{c c}=\varepsilon_{c o}+10^{3}\left(3 k-150 k^{2}\right) / f_{c o}^{\prime}
$$

where $\varepsilon_{c o}$ is the ultimate axial strain of unconfined concrete $\left(\varepsilon_{c o}=0.002\right.$ for concrete strength of 20.7MPa (3ksi) and 0.0024 for 41.4MPa (6ksi) concrete strength). 


\section{Youssef (2004)}

In this model, the stress-strain curve consists of two parts. The first portion is a polynomial curve extending from the initial conditions $\left(f_{c}, \varepsilon_{c}=0,0\right)$ to a transition point $\left(f_{t}, \varepsilon_{t}\right)$ loading. The second portion begins at the transition point and extends linearly to the ultimate compressive strength of the confined concrete. The curve in this region can be either ascending or descending depending on the amount of FRP applied to the concrete core and the cross sectional geometry.

For stress-strain curves in which the second portion is ascending $\left(E_{2}>0\right)$ and determined by the coordinates $\left(f_{t}, \varepsilon_{t}\right.$ and $\left.f_{c c}^{\prime}, \varepsilon_{c c}\right)$,

$$
f_{c}=E_{c} \varepsilon_{c}\left[1-\frac{1}{n}\left(1-\frac{E_{2}}{E_{c}}\right)\left(\frac{\varepsilon_{c}}{\varepsilon_{t}}\right)^{n-1}\right] \quad\left(E_{2}>0\right)
$$

where $0 \leq \varepsilon_{c} \leq \varepsilon_{t}$ and

$$
n=\frac{\left(E_{c}-E_{2}\right) \varepsilon_{t}}{E_{c} \varepsilon_{t}-f_{t}}
$$

In a case where the second portion is descending $\left(E_{2}<0\right)$,

$$
f_{c}=E_{c} \varepsilon_{c}\left[1-\frac{1}{n}\left(\frac{\varepsilon_{c}}{\varepsilon_{t}}\right)^{n-1}\right]\left(E_{2}<0\right)
$$

where $0 \leq \varepsilon_{c} \leq \varepsilon_{t}$.

The coordinates for the transition point are predicted by equations derived by regression analysis:

$$
f_{t}=f_{c o}^{\prime}\left[1.0+1.1350\left(\frac{\rho_{f} E_{f} \varepsilon_{j t}}{f_{c o}^{\prime}}\right)^{\frac{5}{4}}\right]
$$




$$
\varepsilon_{t}=0.002+0.0775\left(\frac{\rho_{f} E_{f} \varepsilon_{j t}}{f_{c o}^{\prime}}\right)^{\frac{6}{7}}\left(\frac{f_{f r p}}{E_{f}}\right)^{\frac{1}{2}}
$$

where $\varepsilon_{j t}$ is the strain in the FRP at the transition point $(0.002)$ and $f_{f r p}$ is the tensile strength of the FRP sheet.

The ultimate compressive strength $\left(f_{c u}\right)$ and corresponding strain $\left(\varepsilon_{c u}\right)$ of the confined concrete are predicted by equations obtained from regression analysis:

$$
\begin{aligned}
& f_{c u}=f_{c o}^{\prime}\left[0.5+1.225\left(\frac{f_{l}^{\prime}}{f_{c o}^{\prime}}\right)^{\frac{3}{5}}\right] \\
& \varepsilon_{c u}=0.004325+0.2625\left(\frac{f_{l}^{\prime}}{f_{c o}^{\prime}}\right)\left(\frac{f_{f r p}}{E_{f}}\right)^{\frac{1}{2}}
\end{aligned}
$$

where the effective lateral confining stress provided by the FRP wrapping at the ultimate condition $\left(f_{l}^{\prime}\right)$ is given by

$$
f_{l}^{\prime}=k_{e}\left(\frac{1}{2} \rho_{f} f_{f r p}\right)
$$

\section{Cusson and Paultre (1994)}

This model predicts the compressive strength of confined concrete as:

$$
f_{c c}^{\prime}=f_{c o}^{\prime}\left[1+2.1\left(\frac{f_{l}^{\prime}}{f_{c o}^{\prime}}\right)^{0.7}\right] \text {. }
$$

\section{Razvi and Saatacioglu (1994)}

In this model, the compressive strength is given by the additive relation: 


$$
f_{c c}^{\prime}=f_{c o}^{\prime}+6.7\left(f_{l}^{\prime}\right)^{0.83}
$$

\section{Frangou et al. (1995)}

This model, used as a design tool in Eurocode 8, specifies the increase in the maximum compressive strength due to the applied lateral pressure as:

$$
\begin{array}{ll}
f_{c c}^{\prime}=f_{c o}^{\prime}\left(1.125+1.25 \alpha \omega_{w}\right) & \alpha \omega_{w} \geq 0.1 \\
f_{c c}^{\prime}=f_{c o}^{\prime}\left(1+2.5 \alpha \omega_{w}\right) & \alpha \omega_{w} \leq 0.1
\end{array}
$$

where $\alpha$ is a reduction factor, expressing the effectiveness of confinement, and $\omega_{w}$ is the volumetric mechanical ratio.

\section{Wang and Restrepo (2001)}

This model holds for both square and rectangular columns. It is based on prior work performed by Mander et al. (1988) who developed a model to calculate the increase in concrete compressive strength due to confining pressure provided by transverse reinforcement in reinforced concrete columns.

In the case of a rectangular section, the confining pressures in mutually orthogonal directions, $f_{l x}$ and $f_{l y}$ are different. The confined concrete strength is given by

$$
f_{c c}^{\prime}=\alpha_{1} \alpha_{2} f_{c o}^{\prime}
$$

where

$$
\alpha_{1}=1.25\left[1.8 \sqrt{\left(1+7.84 f_{l x} / f_{c o}^{\prime}\right)}-1.6 f_{l x} / f_{c o}^{\prime}-1\right]
$$

and

$$
\alpha_{2}=\left[1.4 f_{l y} / f_{l x}-0.6\left(f_{l y} / f_{l x}\right)^{2}-0.8 \sqrt{f_{l x} / f_{l y}}+1\right]
$$




\section{Harajli et al. (2006)}

This model is an extension of the ACI 440 model discussed earlier. The compressive strength of confined concrete is given by:

$$
f_{c c}^{\prime}=f_{c o}^{\prime}+k_{1}\left(f_{l f}+f_{l s} \frac{A_{c}}{A_{g}}\right)
$$

The value of the confinement effectiveness coefficient, $k_{1}=1.25\left(\frac{f_{l f}+f_{l s} A_{c c} / A_{g}}{f_{c}^{\prime}}\right)^{-0.5}$, where $2 \leq k_{1} \leq 7$

\section{Restrepo and Vino (1996)}

In this model, the axial compressive strength of the confined member is:

$$
f_{c c}^{\prime}=\alpha_{1} \alpha_{2} f_{c o}^{\prime}
$$

with

$$
\alpha_{1}=2.254 \sqrt{1+7.94 \frac{f_{\ell x}}{f_{c o}^{\prime}}}-2 \frac{f_{\ell x}}{f_{c o}^{\prime}}-1.254
$$

and

$$
\alpha_{2}=1-\left[0.6\left(\frac{f_{\ell y}}{f_{\ell x}}\right)^{2}-1.4 \frac{f_{\ell y}}{f_{\ell x}}+0.8\right] \sqrt{\frac{f_{\ell x}}{f_{c o}^{\prime}}}
$$

where $f_{l x}$ and $f_{l y}$ are the lateral confinement pressures induced by the FRP wrapping reinforcement on a square or rectangular cross-section in $\mathrm{x}$ and $\mathrm{y}$ directions, respectively.

\section{International Conference of Building Official (ICBO 1997)}

For rectangular sections with an aspect ratio $(b / d)$ less than 1.5 , the enhanced compressive strength is given by:

$$
f_{c c}^{\prime}=f_{c o}^{\prime}\left(1+5 \rho_{f} \cos ^{2} \theta\right)
$$




\section{Lam and Teng (2003)}

This design-oriented model is an extension of a stress-stain model initially developed for uniformly confined concrete columns having circular cross sections. For a rectangular section, the compressive strength and ultimate axial strain are predicted by the following equations:

$$
\begin{aligned}
& f_{c c}^{\prime}=f_{c o}^{\prime}+k_{1} k_{s 1} f_{l} \\
& \frac{\varepsilon_{c u}}{\varepsilon_{c o}}=1.75+k_{2} k_{s 2} \frac{f_{l}}{f_{c o}^{\prime}}\left(\frac{\varepsilon_{c l u}}{\varepsilon_{c o}}\right)^{0.45}
\end{aligned}
$$

where the terms $k_{s 1}$ and $k_{s 2}$ are the enhancement factors, and $k_{1}$ and $k_{2}$ are constant values found by means of regression analysis.

\section{Proposed Compressive Strength Model}

The performance of a rectangular FRP-confined concrete column depends on several parameters including the mechanical properties of the confining material and geometrical factors such as the aspect ratio $(b / d)$ and corner radii.

This study has shown that the overall increase in a column's strength reduces with increasing aspect ratio. Square columns experience the highest strength increase while columns fabricated with progressively larger radii lead to higher strength gains. These trends have been observed by others (Matthys 1999; Lam and Teng 2003; Eugene 2005) and must be considered to accurately predict the compressive strength of a large-scale FRP-confined concrete column.

To this end, a model is suggested based on the linear equation initially proposed by Richart et al. (1929) for uniformly confined concrete:

$$
f_{c c}^{\prime}=f_{c o}^{\prime}+k_{1} f_{l}
$$


In the new model, the confinement effectiveness coefficient, $k_{l}$, is augmented as follows:

$$
f_{c c}^{\prime}=f_{c o}^{\prime}+k_{1} k_{c 2} k_{c 3} f_{l}^{\prime} .
$$

The coefficients $k_{c 2}$ and $k_{c 3}$ are introduced to account for variations in corner radius and aspect ratio, respectively. The values of these coefficients are based on the power functions:

$$
k_{c 2}=\left[\frac{2 r}{D}\right]^{\gamma}
$$

and

$$
k_{c 3}=\left[\frac{d}{b}\right]^{\eta}
$$

where $\gamma=0.1, \eta=0.13$, and $k_{1}=4.0$. The latter were determined by conducting a regression analysis on experimental data for sixty-two (62) non-circular columns reported herein and elsewhere (Matthys 1999; Lam and Teng 2003; Eugene 2005). For square columns, the value of $k_{c 3}$ is equal to 1 . The lateral effective confining pressure, $f_{l}$, is given by Eq. 10 which includes the coefficient $k_{e}$ defined in Eq. 5.

An expression for the maximum confining pressure provided by the FRP of an equivalent uniformly confined column $\left(f_{l}\right)$ can be derived by considering equilibrium of forces on a free-body diagram:

$$
f_{l}=\frac{2 E_{f} \varepsilon_{j} t_{j}}{D}
$$

The term $\varepsilon_{j}$ represents the lateral strain in the FRP wrapping recorded at the point of rupture and equals the quantity, $\boldsymbol{\varepsilon}_{c l m}$, as defined previously. This strain is usually lower than the ultimate strain, $\varepsilon_{\text {fum }}$, recorded for a flat FRP coupon.

In general, the effective FRP failure strain, $\boldsymbol{\varepsilon}_{c l u}$, depends on various parameters; the influence and interaction of which are difficult to quantify analytically. So an attempt was made to develop 
an empirical relationship between the effective FRP strain coefficient, $\beta$ and the confining stiffness, $k_{\text {conf. }}$ A plot of these parameters for all 62 columns found in the literature mentioned above is shown in Figure 8.

A regression analysis was performed on this data in an attempt to obtain a simple design equation for the lateral confinement pressure. The analysis revealed that the optimum value of $\beta$ was 0.43 , making:

$$
\varepsilon_{j}=0.43 \varepsilon_{\text {fum }} .
$$

The model can also be applied to an equivalent circular column having a diameter, $D$, given by Eq. 8.

\section{DISCUSSION}

Table 4 shows a comparison of the theoretical compressive strength values, predicted by all of the models cited above, with the experimental results taken for the large-scale columns studied herein. The new model predicts the axial ultimate stress of these field size columns very well.

The new model was also applied to predict the compressive strength of the all of the specimens considered during its development. Figure 9 shows the results for fifty-nine small-scale columns and three field size columns; a good correlation is observed.

\section{CONCLUSIONS}

In this study, the existing ultimate axial strength and stress-strain models are reviewed; and, comparisons made with experimental data taken from large-scale rectangular columns. During this process, a simple design-oriented model was developed to predict the ultimate axial strength. The latter takes into account the confinement effectiveness coefficient, the aspect ratio, and 
corner radii. Due to the cost and labor associated with making large size specimens, this study is based on a limited number of columns. More columns with number of FRP layers should be made to verify the results and the new developed FRP model.

The following conclusions can be drawn for non-circular columns:

1. Higher aspect ratios result in lower confinement strength.

2. Confinement compressive strength increases as the corner radii increase.

3. Models developed by Lam and Teng and Youssef are slightly underestimate the experimental curve except that Youssef's model slightly overestimate the experimental curve in K11. Overall, all models seem to perform quite well in the pre-peak stage. However, the models produce great scatter in terms of predictions of the post-peak behavior. The models developed by Harajili et al. and Youssef have decreasing branches which is quite different from the experimental curve shape. It seems that these two models overly underestimate the test results at the ultimate state. Chaallal's model is intended to over predict the experimental curve in the post-peak region. Also the three-line curve of Chaallal's model does not quite fit the smooth experimental curve. Generally, Lam and Teng's model perform the best among all evaluated models in terms of shape and critical values.

The new model accurately predicts the ultimate axial strength for both small and large scale rectangular columns. However, additional testing on large-scale specimens must be done to better establish validity.

\section{Notation}

The following symbols are used in this paper: 


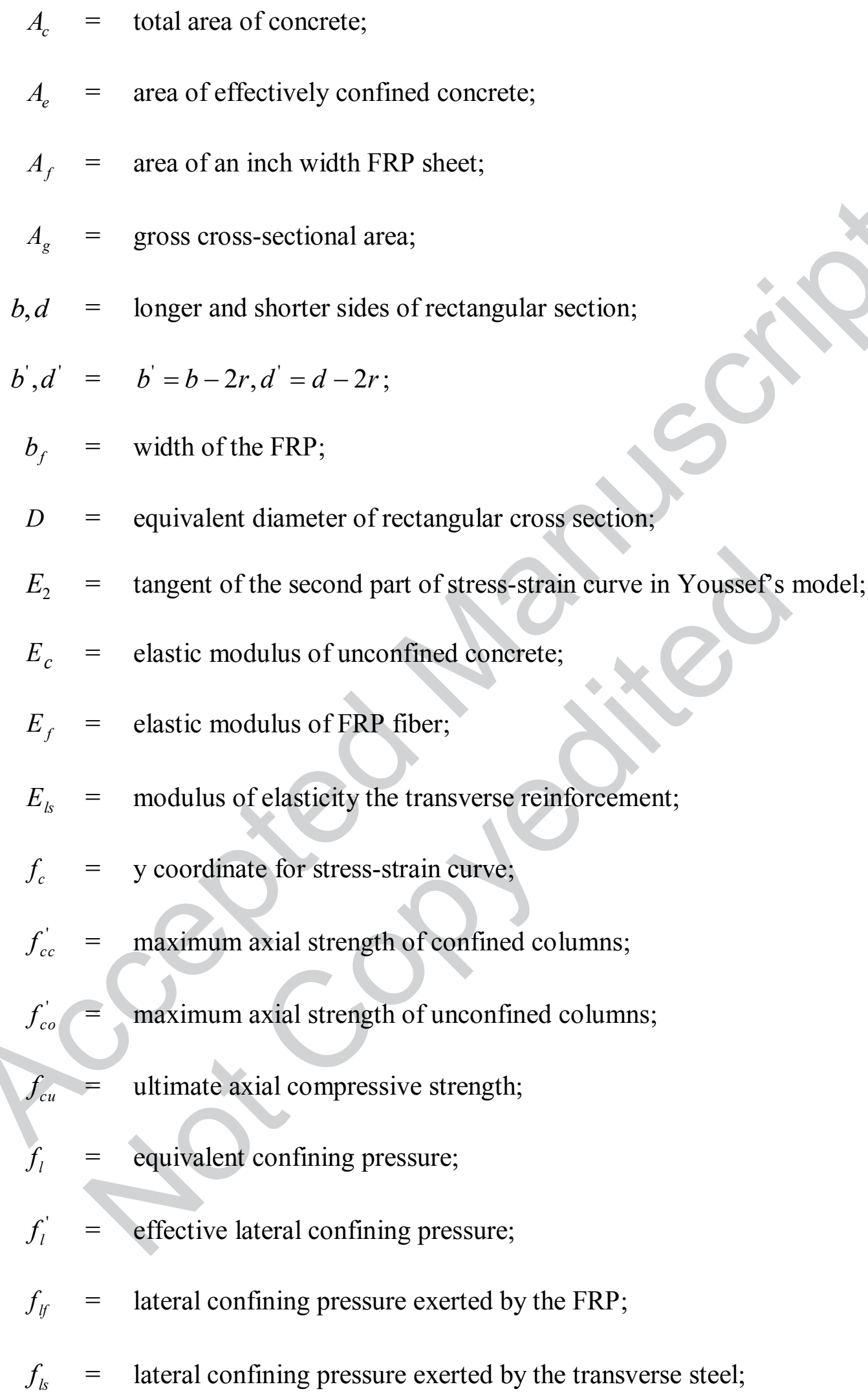




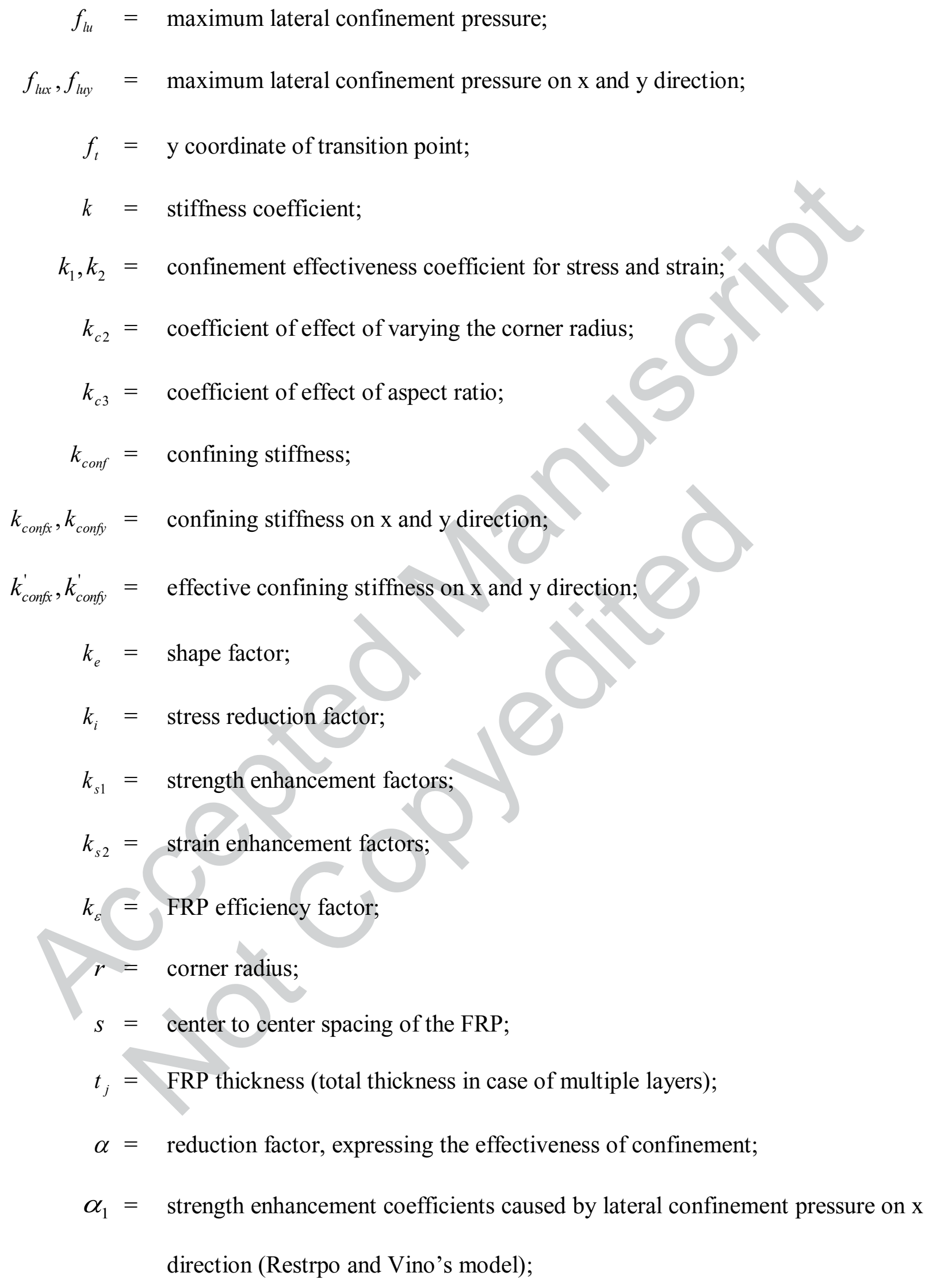


$\alpha_{2}=$ strength enhancement coefficients caused by ratio of lateral confinement pressure on $\mathrm{x}$ and $\mathrm{y}$ direction (Restrpo and Vino's model);

$\beta=$ effective FRP strain coefficient;

$\gamma, \eta=$ coefficients based on regression analysis;

$\varepsilon_{c}=\mathrm{x}$ coordinate of stress-strain curve;

$\varepsilon_{\text {fum }}=$ FRP failure strain;

$\varepsilon_{c 1}=$ axial strain at maximum load;

$\varepsilon_{c u}=$ axial strain at failure load;

$\varepsilon_{c \ell 1}=$ circumferential strain at maximum load;

$\varepsilon_{c l u}=$ circumferential strain at failure load;

$\varepsilon_{c o}=$ ultimate axial strain of unconfined concrete columns;

$\varepsilon_{j}=$ nominal hoop rupture strain of an equivalent circular column;

$\varepsilon_{j t}=$ strain in the FRP at the transition point;

$\varepsilon_{\ell o}=$ yield strain of ordinary transverse hoops or 0.002 if no internal confinement by ordinary transverse steel is available;

$\varepsilon_{t}=\mathrm{x}$ coordinate of transition point;

$\varepsilon_{y t}=$ yield strain of ordinary transverse hoops;

$\theta=$ angle of inclination of the fibers to the longitudinal axis of the member;

$\rho_{f}=$ quantities of transverse confining reinforcement;

$\rho_{f x}, \rho_{f y}=$ quantities of transverse confining reinforcement in the $\mathrm{x}$ and $\mathrm{y}$ direction; 
$\rho_{s g}=$ reinforcement ratio of the longitudinal steel reinforcement with respect to the gross sectional area;

$\sigma_{j}=$ nominal hoop rupture stress in the FRP jacket;

$\omega_{w}=$ volumetric mechanical ratio. 


\section{REFERENCES}

ACI Committee 440 Report. (2002). "Guide for the design and construction of externally bonded FRP systems for strengthening concrete structure.” ACI 440.2R-02, Detroit.

Campione, G., and Miraglia, N. (2003). "Strength and strain capacities of concrete compression members reinforced with FRP." Cem. Concr. Compos., 25:31-41.

Campione, G., Miraglia, N., and Papia, M. (2004). "Strength and strain enhancements of concrete columns confined with FRP sheets.” Struct. Eng. Mech., 18(6): 769-790.

Campione, G., Miraglia, N., and Papia, M. (2006). "Influence of radius of corners in concrete columns confined with FRP sheets." 3rd Int. Conf. on FRP Compos. in Civ. Eng., Miami ,Florida, USA. (On CD-ROM).

Chaallal, O., and Shahawy, M. (2000). "Performance of fiber-reinforced polymer-wrapped reinforced concrete column under combined axial-flexural loading." ACI Struct. J., 97(4):659-668.

Chaallal, O., Hassan, M., and Shahawy, M. (2003). "Confinement model for axially loaded short rectangular columns strengthened with fiber-reinforced polymer wrapping." ACI Struct. J., $100(2): 215-221$.

Cusson, D., and Paultre, P. (1994). "Confinement model for high-strength concrete tied columns." Report MS-93/02, 54 pages, University of Sherbrooke, Canada.

Eugene, A. (2005). "Stress-strain behavior of rectangular columns confined with CFRP composites." Master's Thesis, University of Alabama in Huntsville, Huntsville, AL.

Frangou, M., Pilakoutas, K., and Dritsos, S.E. (1995). "Structural repair/strengthening of RC columns." Constr. and Building Mater., 9(5): 259-265. 
Harajli, M.H., Hantouche, E., and Soudki, K. (2006). "Stress-strain model for fiber-reinforced polymer jacketed concrete columns." ACI Struct. J., 103(69):672-681.

ICBO. (1997). “Acceptance criteria for concrete and reinforced and unreinforced masonry strengthening using fiber-reinforced composite systems." ICBO Evaluation Service, Whittier, California.

Jiang, T., and Teng, J.G. (2006). "Strengthening of short circular RC columns with FRP jackets: a design proposal." 3rd Int. Conf. on FRP Compos. in Civ. Eng., Miami,Florida, USA. (On CD-ROM)

Lam, L., and Teng, J.G. (2003). "Design-oriented stress-strain model for FRP-confined concrete in rectangular columns." J. of Reinforced Plastics and Compos., 22(13): 1149-1185.

Mander, J.B., Priestley, M.J.N., and Park, R. (1988). "Theoretical stress-strain model for confined concrete.” J. Struct. Eng., ASCE, 114(8): 1804-1826.

Matthys, S. (1999). "Structural behavior and design of concrete members strengthened with externally bonded FRP reinforcement." Thesis in fulfillment of the requirements for the degree of Doctor of Applied Sciences, option Structural Engineering. Ghent University, Belgium. 345 Pages.

Matthys, S., Toutanji, H., Audenaert, K., and Taerwe, L. (2005). "Axial load behavior of large-scale columns confined with fiber-reinforced polymer composites." ACI Struct. J., 102(2):258-267.

Matthys, S., Toutanji, H., and Taerwe, L. (2006). "Stress-strain behavior of large-scale circular columns confined with FRP composites.” J. Struct. Eng., ASCE, 132(1): 123-133.

Mirmiran, A., and Shahawy, M. (1997). "Behavior of concrete columns confined by fiber composites." J. Struct. Eng., ASCE, 123(5): 583-590. 
Razvi, S.R., and Saatcioglu, M. (1994). "Strength and deformability of confined high-strength concrete columns.” ACI Struct. J., 91(6): 678-687.

Restrepo, J.I., and Vino, B.D. (1996). "Enhancement of the axial load carrying capacity of reinforced concrete columns by means of fiber glass-epoxy jackets." Proc., 2nd. Int. Conf. On Adv. Compos. Mater. in Brid. Struct., 547-554, the Canadian Society for Civil Engineering, Montreal, Quebec, Canada.

Richart, F.E., Brandtzaeg, A., and Brown, R.L. (1929). "The failure of plain and spirally reinforced concrete in compression." Bulletin 190, University of Illinois Engineering Experimental Station, Champaign, Illinois.

Spoelstra, M.R., and Monti, G. (1999). "FRP-confined concrete model." J. Compos. Constr., ASCE, 3(3): 143-150.

Youssef, M.N. (2004). "Stress-strain model for concrete confined by FRP composites." Ph.D. Dissertation, University of California, Irvine.

Wang, Y.C., and Restrepo, J.I. (2001). "Investigation of Concentrically Loaded Reinforced Concrete Columns Confined with Glass Fiber-Reinforced Polymer Jackets.” ACI Struct. J., $98(3): 377-385$. 
Table 1-Test parameters of wrapped columns

\begin{tabular}{|c|c|c|c|c|c|c|c|}
\hline Spec. & $\begin{array}{c}\text { Column shape } \\
{[\mathrm{mm}]} \\
\mathrm{in} .\end{array}$ & $\begin{array}{c}\text { Age at } \\
\text { test } \\
\text { days }\end{array}$ & $\begin{array}{c}\mathrm{f}^{\prime} \text { co } 28 \text { days } \\
{\left[\mathrm{N} / \mathrm{mm}^{2}\right]} \\
k s i\end{array}$ & $\begin{array}{c}\text { FRP } \\
\text { type }\end{array}$ & $\begin{array}{c}\text { No. of } \\
\text { layers }\end{array}$ & $\begin{array}{c}\text { Width } \\
{[\mathrm{mm}]} \\
\text { in. }\end{array}$ & Wrapping \\
\hline $\mathrm{K} 1$ & $\varnothing 400$ & 29 & 31.8 & - & - & - & - \\
\hline $\mathrm{K} 9$ & $355 \times 355 / \mathrm{r} 30$ & 29 & 39.1 & TU600/25 & 2 & 200 & Full \\
& $14 \times 14 / \mathrm{r} 1.18$ & & $(5.67)$ & & & $(7.87)$ & \\
\hline K10 & $355 \times 355 / \mathrm{r} 15$ & 28 & 37.7 & TU600/25 & 2 & 200 & Full \\
& $14 \times 14 / \mathrm{r} 0.59$ & & $(5.47)$ & & & $(7.87)$ & \\
\hline K11 & $250 \times 500 / \mathrm{r} 30$ & 29 & 37.7 & TU600/25 & 2 & 200 & Full \\
& $9.8 \times 19.7 / \mathrm{r} 1.18$ & & $(5.47)$ & & & $(7.87)$ & \\
\hline
\end{tabular}

Table 2-Mean tensile properties obtained by tensile testing

\begin{tabular}{|l|c|c|c|c|c|}
\hline \multicolumn{1}{|c|}{ Type } & $\begin{array}{c}\text { Nominal } \\
\text { Dimensions } \\
{[\mathrm{mm}]} \\
\mathrm{in.}\end{array}$ & $\begin{array}{c}f_{y}{ }^{(3)} \\
{\left[\mathrm{N} / \mathrm{mm}^{2}\right]} \\
k s i\end{array}$ & $\begin{array}{c}f_{t}^{(4)} \\
{\left[\mathrm{N} / \mathrm{mm}^{2}\right]} \\
k s i\end{array}$ & $\begin{array}{c}\text { Ultimate } \\
\text { strain } \\
{[\%]}\end{array}$ & $\begin{array}{c}\mathrm{E} \\
{\left[\mathrm{N} / \mathrm{mm}^{2}\right]} \\
\mathrm{ksi}\end{array}$ \\
\hline Rebar & $\varnothing 8$ & 560 & 610 & 2.77 & $2 \times 10^{5}$ \\
S500 & $\varnothing 0.31$ & 81.2 & 88.5 & & $2.9 \times 10^{4}$ \\
\hline & $\varnothing 14$ & 560 & 630 & 9.97 & $2 \times 10^{5}$ \\
\hline TU600/25 & $\varnothing 0.55$ & 81.2 & 91.4 & & $2.9 \times 10^{4}$ \\
\hline -PC5800 & $7.87 \times 0.01$ & - & 780 & 1.30 & $6 \times 10^{4(2)}$ \\
\hline
\end{tabular}

\footnotetext{
(1) Equivalent dry-fiber thickness

${ }^{(2)}$ Tangent modulus at the origin

${ }^{(3)}$ Yield strength

${ }^{(4)}$ Tensile strength
} 
Table 3-Test results of compression tests on columns

\begin{tabular}{|c|c|c|c|c|c|c|c|c|}
\hline \multirow[t]{2}{*}{ Spec. } & 1 & 2 & 3 & 4 & 5 & 6 & 7 & 8 \\
\hline & $\underset{[k N] k i p}{Q_{\max }}$ & $\begin{array}{c}Q_{\max } / A_{g} \\
{\left[\mathrm{~N} / \mathrm{mm}^{2}\right] \mathrm{ksi}}\end{array}$ & $\begin{array}{c}Q / Q_{\text {ref }} \\
{[-]}\end{array}$ & $\begin{array}{c}\mathcal{E}_{c 1} \\
{[\mathrm{~mm} / \mathrm{m}]}\end{array}$ & $\begin{array}{c}\mathcal{E}_{c u} \\
{[\mathrm{~mm} / \mathrm{m}]}\end{array}$ & $\begin{array}{c}\boldsymbol{\varepsilon}_{\mathbf{c} \ell \mathbf{1}} \\
{[\mathrm{mm} / \mathrm{m}]}\end{array}$ & $\begin{array}{c}\boldsymbol{\varepsilon}_{\mathbf{c} \ell \mathbf{u}} \\
{[m m / m]}\end{array}$ & $\begin{array}{c}\boldsymbol{\varepsilon}_{\mathbf{c} \ell \mathbf{u}} / \varepsilon_{f u m} \\
{[-]}\end{array}$ \\
\hline K1 & $4.7 \times 10^{3}$ & 37.3 & 1.00 & 2.8 & 3.1 & 1.7 & 1.8 & - \\
\hline K9 & $\begin{array}{l}5.4 \times 10^{3} \\
1.2 \times 10^{3}\end{array}$ & $\begin{array}{l}43.8 \\
6.35\end{array}$ & 1.12 & 3.7 & 3.7 & 2.1 & 2.1 & 0.16 \\
\hline K10 & $\begin{array}{l}5.1 \times 10^{3} \\
1.2 \times 10^{3}\end{array}$ & $\begin{array}{l}41.3 \\
5.98\end{array}$ & 1.09 & 3.2 & 4.2 & 1.8 & 3.4 & 0.26 \\
\hline K11 & $\begin{array}{l}5.0 \times 10^{3} \\
1.1 \times 10^{3}\end{array}$ & $\begin{array}{l}40.6 \\
5.88\end{array}$ & 1.07 & 1.8 & $1.9^{(1)}$ & 0.6 & $0.9^{(1)}$ & $0.07^{(1)}$ \\
\hline
\end{tabular}

${ }^{(1)}$ Failure of the FRP at the column end (strain measurements located in central zone)

$\mathrm{Q}_{\max }$ : maximum load;

Qref: maximum load of unwrapped column;

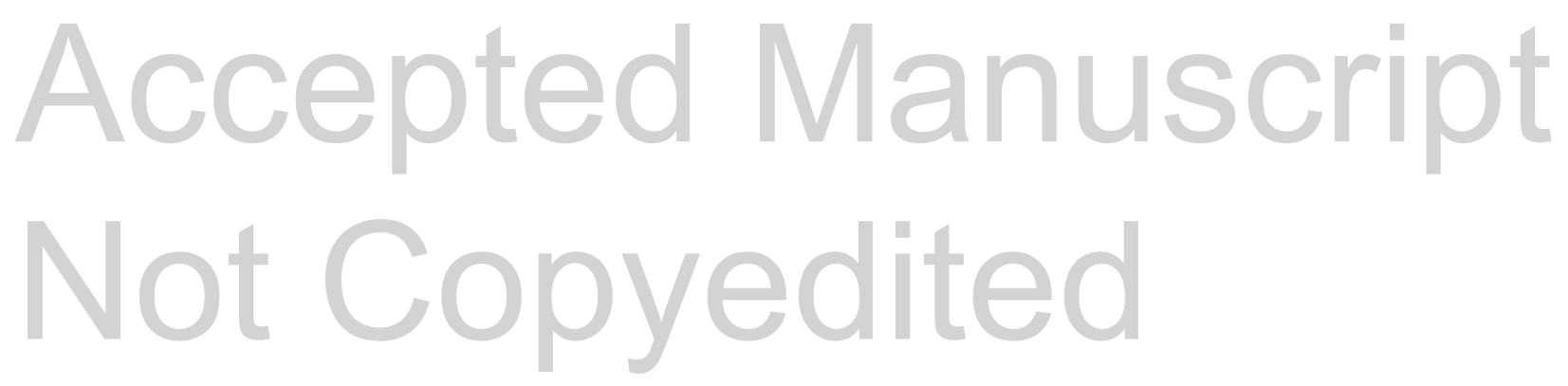


Table 4-Comparison of difference ratio for $f_{c c}^{\prime}$ between each model and experimental data

\begin{tabular}{|c|c|c|c|}
\hline$f_{c c}^{\prime}$ for Each Model $f_{c c}^{\prime}$ for Each Specimen & $\begin{array}{l}\mathrm{K} 9 \\
43.8 \mathrm{MPa} \\
6.35 \mathrm{ksi}\end{array}$ & $\begin{array}{c}\mathrm{K} 10 \\
41.3 \mathrm{MPa} \\
5.98 \mathrm{ksi}\end{array}$ & $\begin{array}{c}\mathrm{K} 11 \\
40.6 \mathrm{MPa} \\
5.88 \mathrm{ksi}\end{array}$ \\
\hline ACI 440 & $-4.0 \%$ & $-8.2 \%$ & $-6.6 \%$ \\
\hline Harajli & $40.9 \%$ & $44.4 \%$ & $41.3 \%$ \\
\hline Lam and Teng & $-6.3 \%$ & $-3.8 \%$ & $-5.3 \%$ \\
\hline Mirmiran & $-6.2 \%$ & $-5.2 \%$ & $-6.3 \%$ \\
\hline Campione and Miraglia & $-4.6 \%$ & $-3.9 \%$ & - \\
\hline Challal & $5.5 \%$ & $9.9 \%$ & $11.7 \%$ \\
\hline Youssef & $-9.8 \%$ & $-6.8 \%$ & $-5.3 \%$ \\
\hline Cusson and Paultre & $-2.7 \%$ & $-3.4 \%$ & $0.7 \%$ \\
\hline Razvi and Saatacioglu & $-3.1 \%$ & $0.2 \%$ & $0.2 \%$ \\
\hline Richart & $-6.6 \%$ & $-4.1 \%$ & $-3.0 \%$ \\
\hline ICBO & $-7.7 \%$ & $-4.5 \%$ & - \\
\hline Frangou & $-6.5 \%$ & $-3.2 \%$ & $-2.1 \%$ \\
\hline Restrepo and Vino & $-2.9 \%$ & $-0.84 \%$ & $-1.1 \%$ \\
\hline New proposed & $-0.61 \%$ & $-0.24 \%$ & $1.1 \%$ \\
\hline
\end{tabular}


List of figures captions:

Fig. 1 Column dimensions and wrapping configuration.

Fig. 2 Confined concrete columns failed by fracture of the FRP after testing.

Fig. 3 Stress-strain behavior of non-circular columns.

Fig. 4 Effective confined region of rectangular column due to arching action. (ACI Committee 440 Report 2002)

Fig. 5 Evaluation of the stress-strain models against tested column specimen K9.

Fig. 6 Evaluation of the stress-strain models against tested column specimen K10.

Fig. 7 Evaluation of the stress-strain models against tested column specimen K11.

Fig. 8 Effective FRP Failure Strain coefficient.

Fig. 9 Performance of newly proposed strength model against 59 data points. 

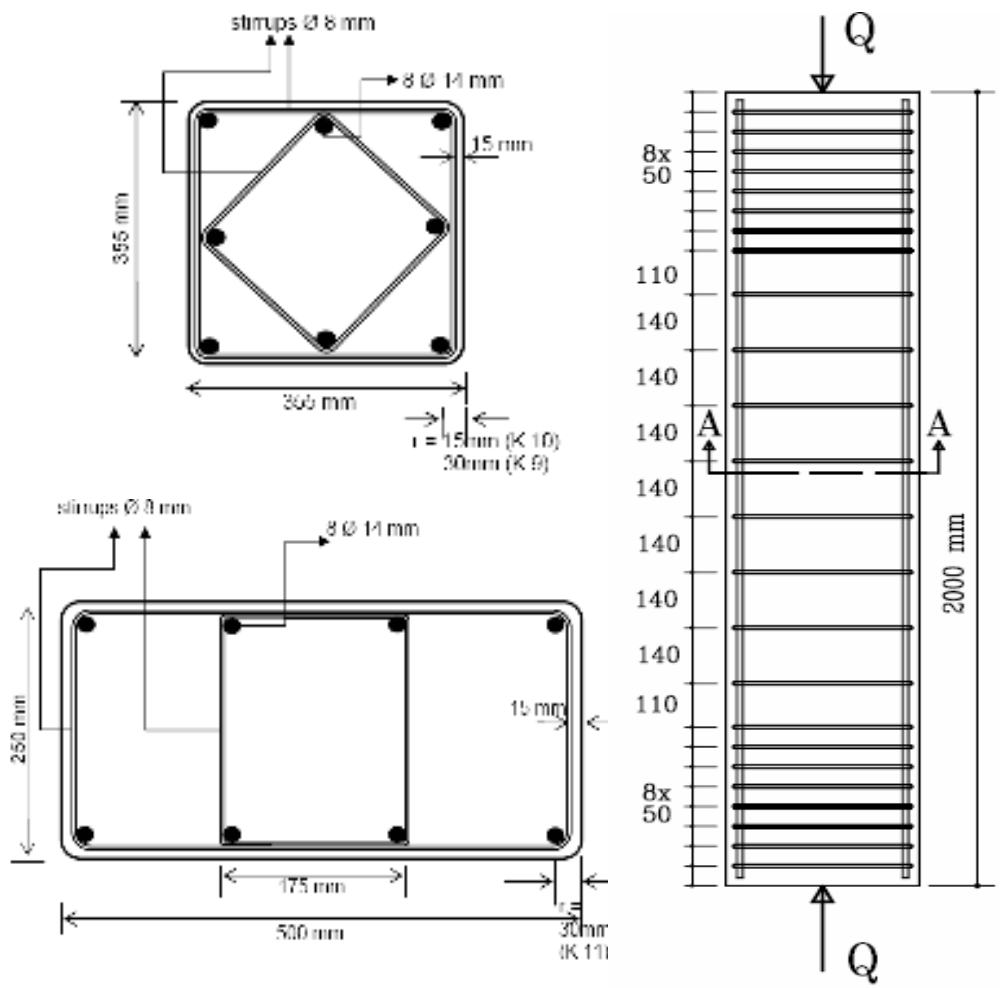

Fig. 1 Column dimensions and wrapping configuration.

(Note: $1 \mathrm{~mm}=0.04 \mathrm{in})$

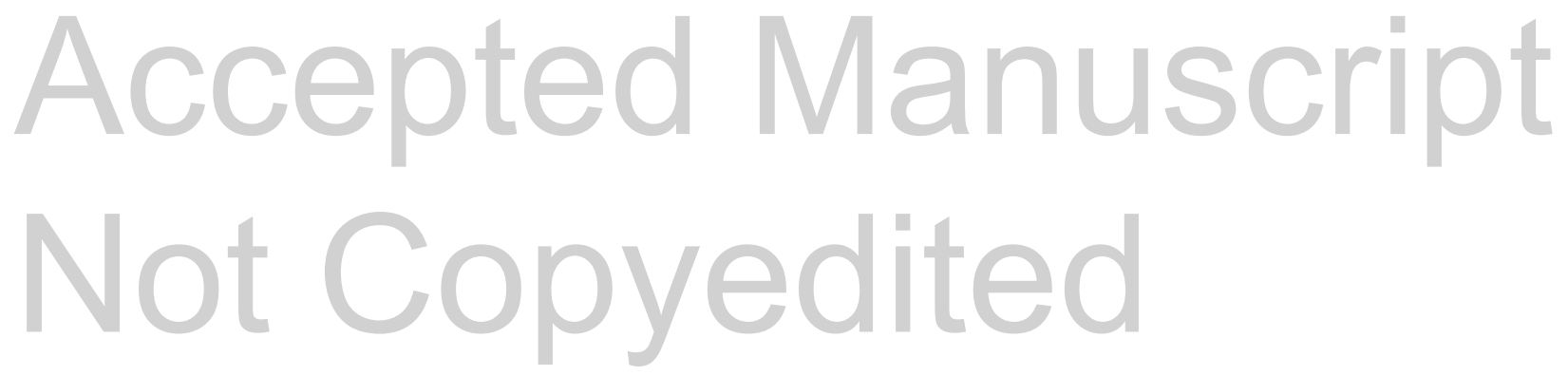


Fig. 2.pdf

Journal of Composites for Construction. Submitted June 10, 2008; accepted June 11, 2009; posted ahead of print June 22, 2009. doi:10.1061/(ASCE)CC.1943-5614.0000051

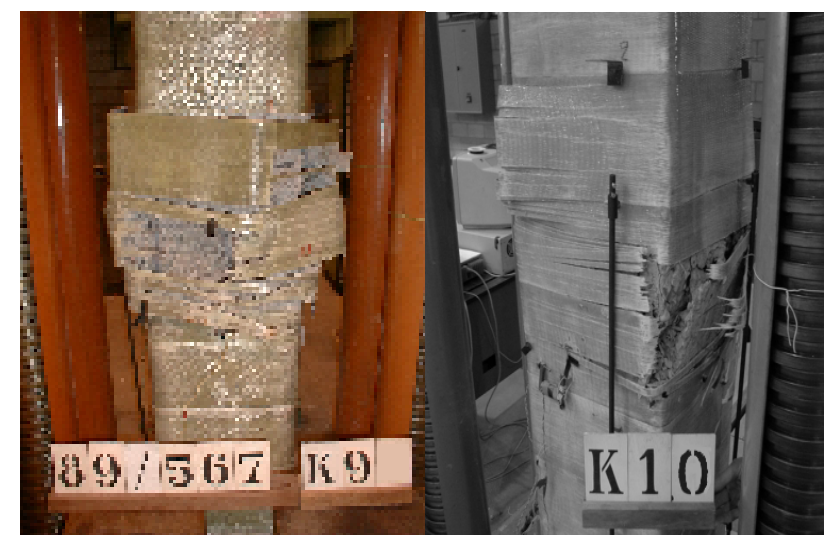

Fig. 2 Confined concrete columns failed by fracture of the FRP after testing

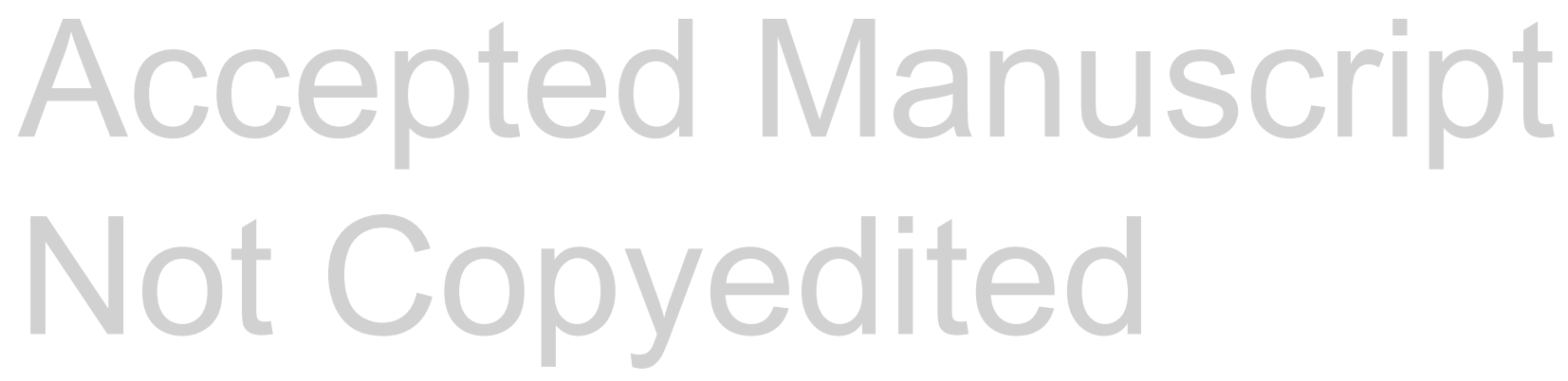



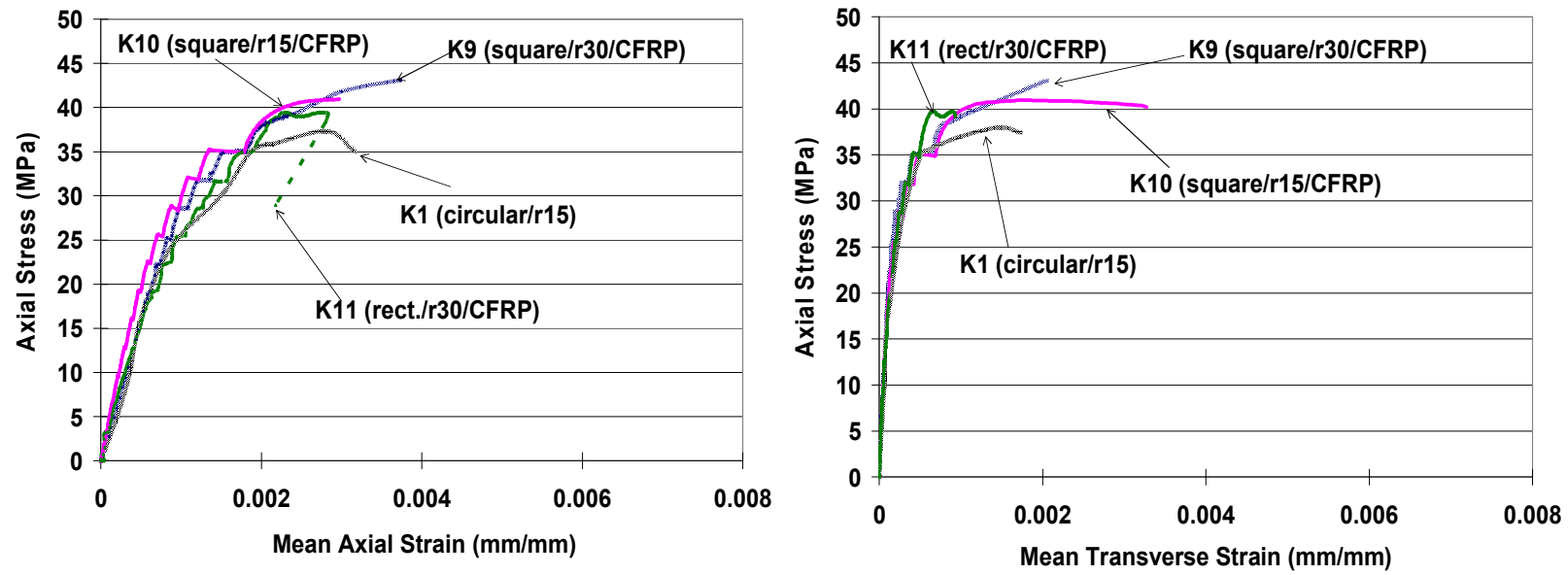

Fig. 3 Stress-strain behavior of non-circular columns. (Note: $1 \mathrm{MPa}=0.145 \mathrm{ksi}$ )

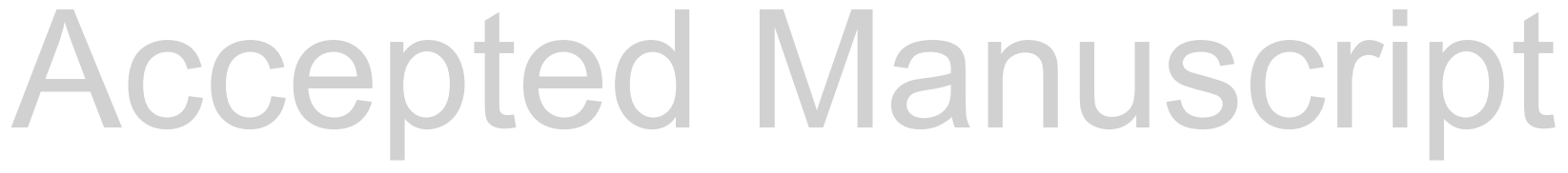
Not Copyedited 


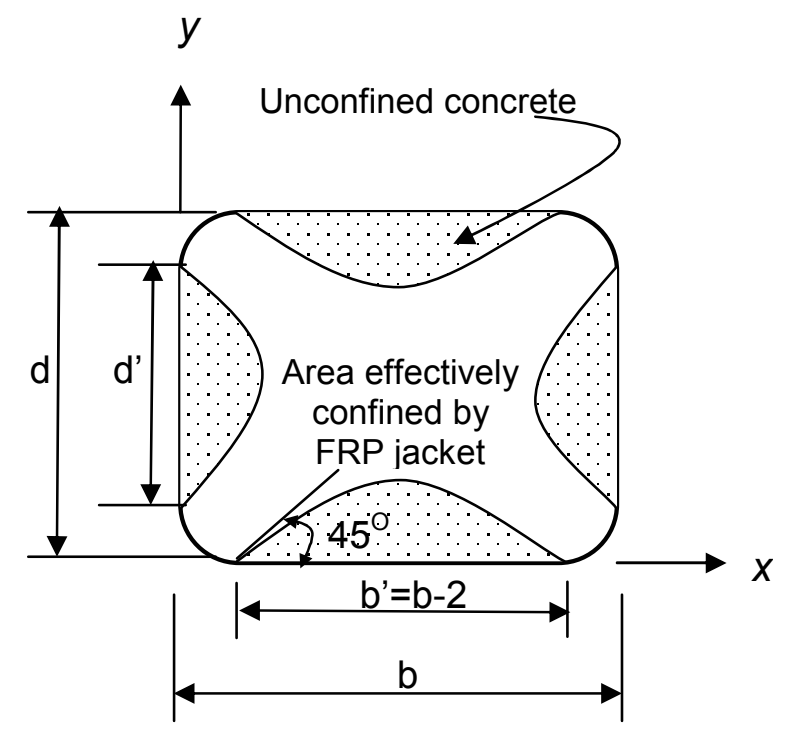

Fig. 4 Effective confined region of rectangular column due to arching action (ACI Committee 440 Report 2002)

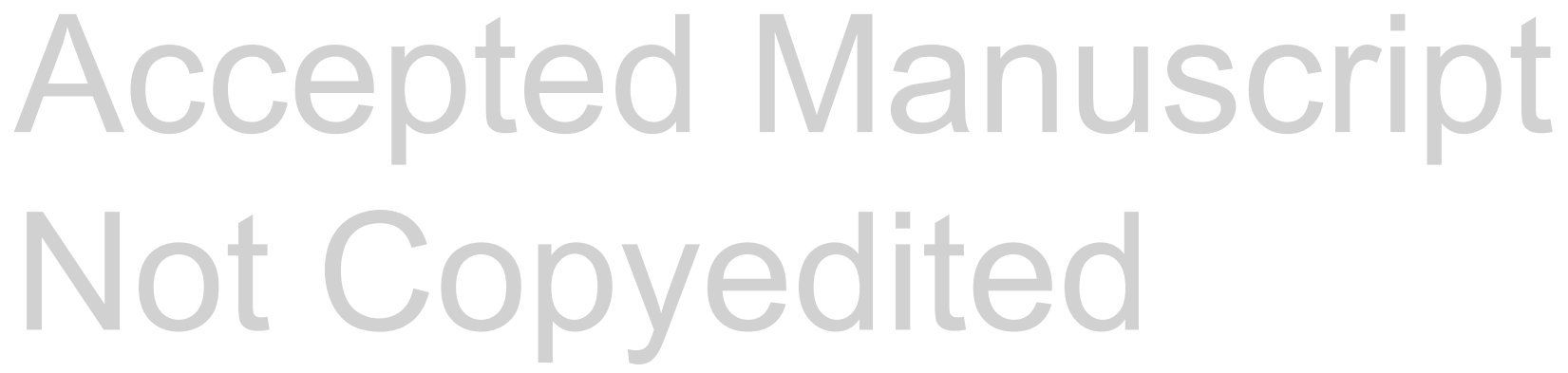


Fig. 5.pdf

Journal of Composites for Construction. Submitted June 10, 2008; accepted June 11, 2009; posted ahead of print June 22, 2009. doi:10.1061/(ASCE)CC.1943-5614.0000051

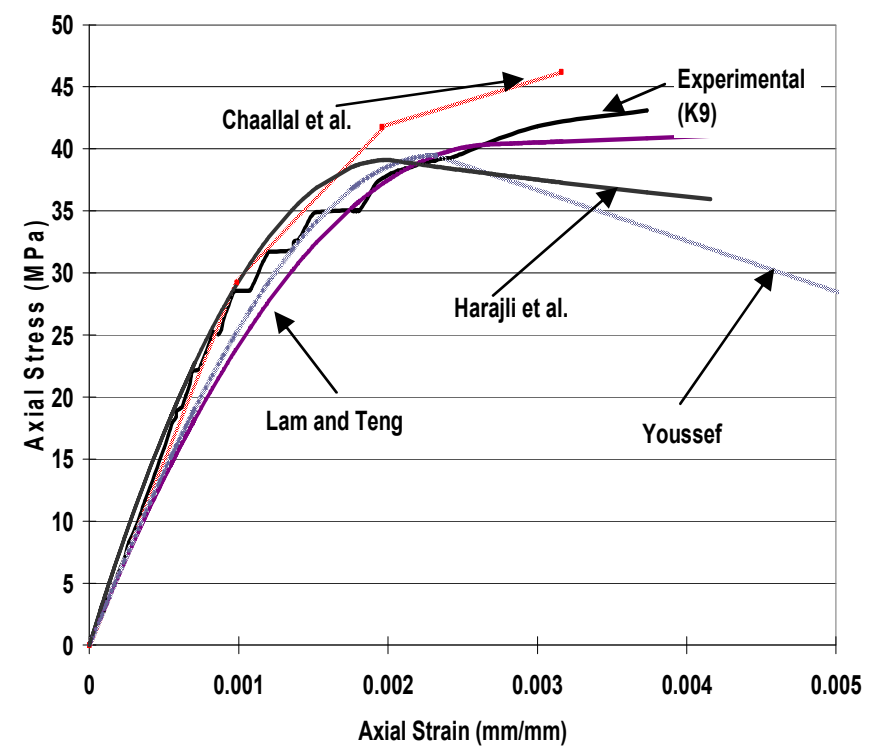

Fig. 5 Evaluation of the stress-strain models against tested column specimen K9. (Note: $1 \mathrm{MPa}=0.145 \mathrm{ksi}$ ).

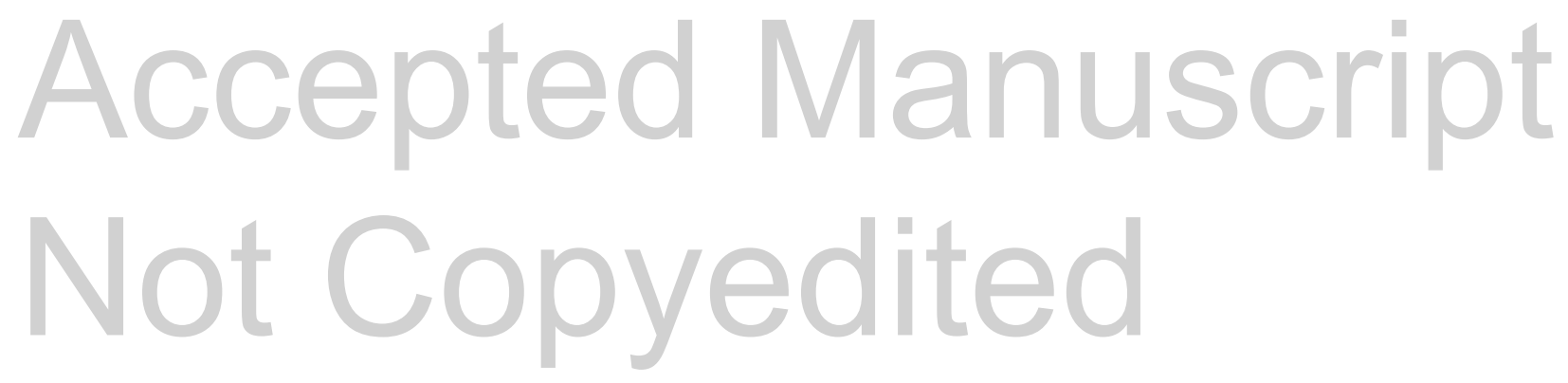


Journal of Composites for Construction. Submitted June 10, 2008; accepted June 11, 2009; posted ahead of print June 22, 2009. doi:10.1061/(ASCE)CC.1943-5614.0000051

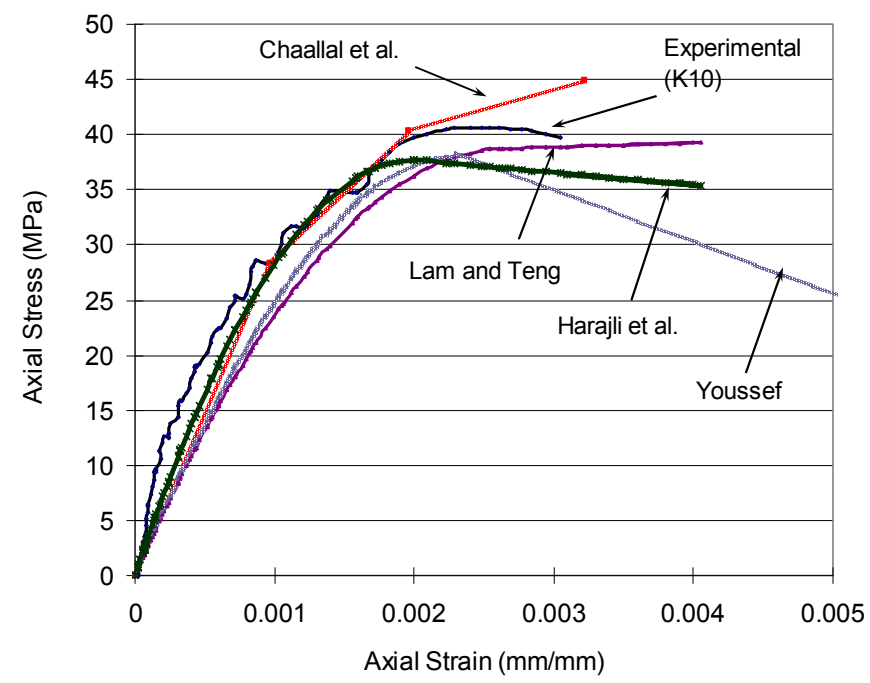

Fig. 6 Evaluation of the stress-strain models against tested column specimen K10. (Note: $1 \mathrm{MPa}=0.145 \mathrm{ksi}$ ).

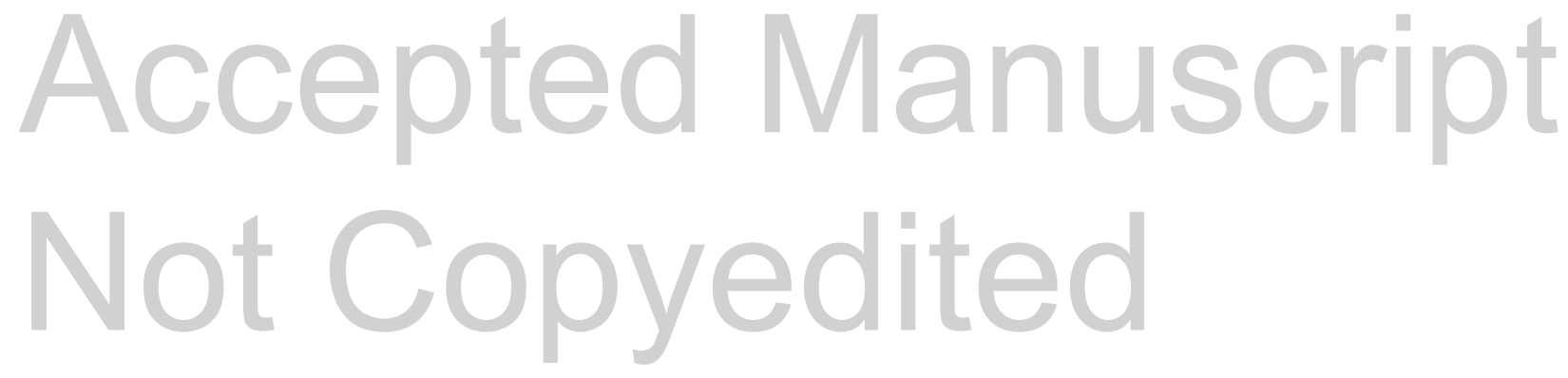




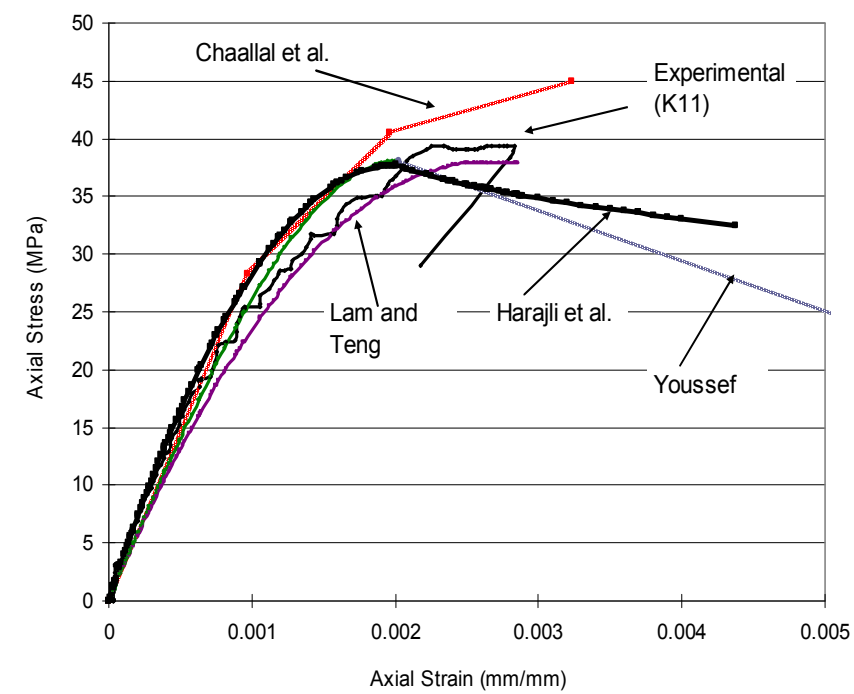

Fig. 7 Evaluation of the stress-strain models against tested column specimen K11. (Note: $1 \mathrm{MPa}=0.145 \mathrm{ksi}$ ).

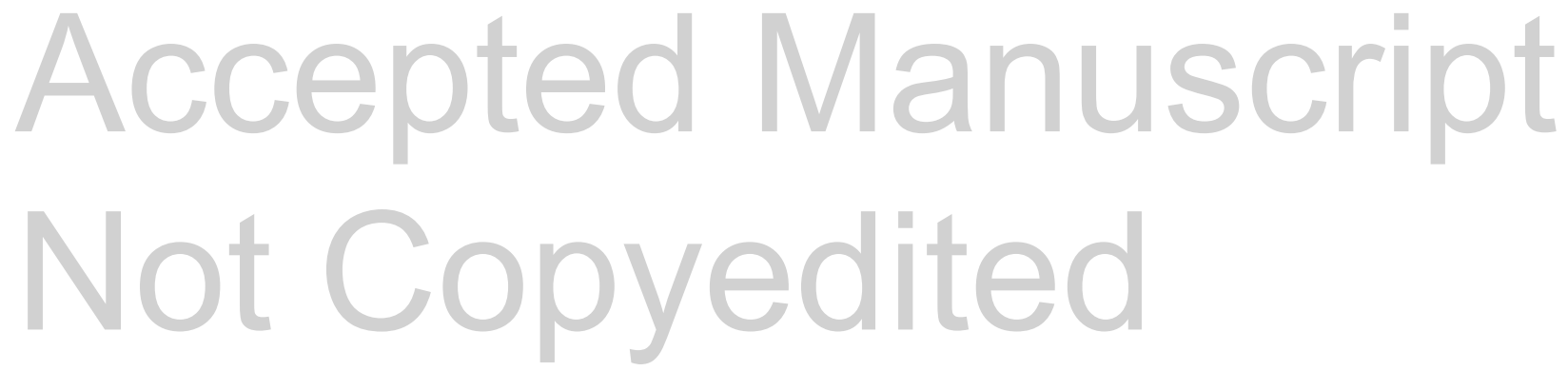


Fig. 8.pdf

Journal of Composites for Construction. Submitted June 10, 2008; accepted June 11, 2009; posted ahead of print June 22, 2009. doi:10.1061/(ASCE)CC.1943-5614.0000051

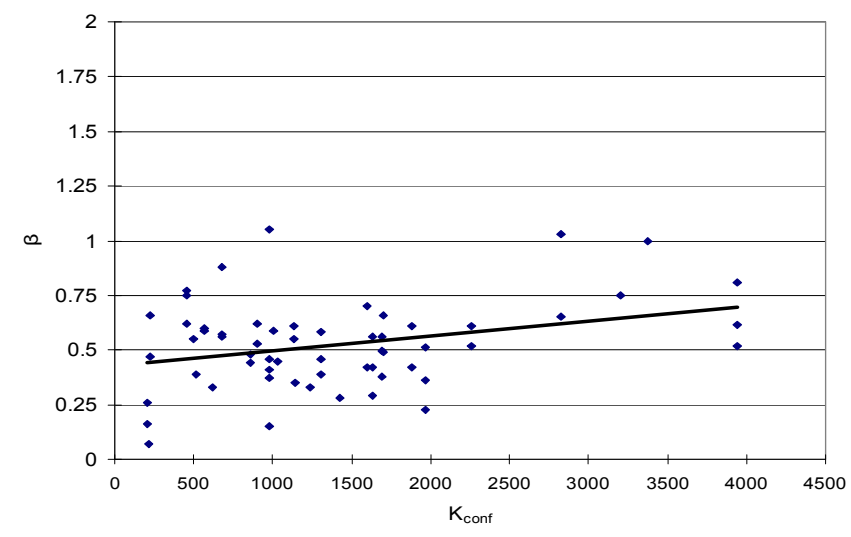

Fig. 8 Effective FRP Failure Strain coefficient

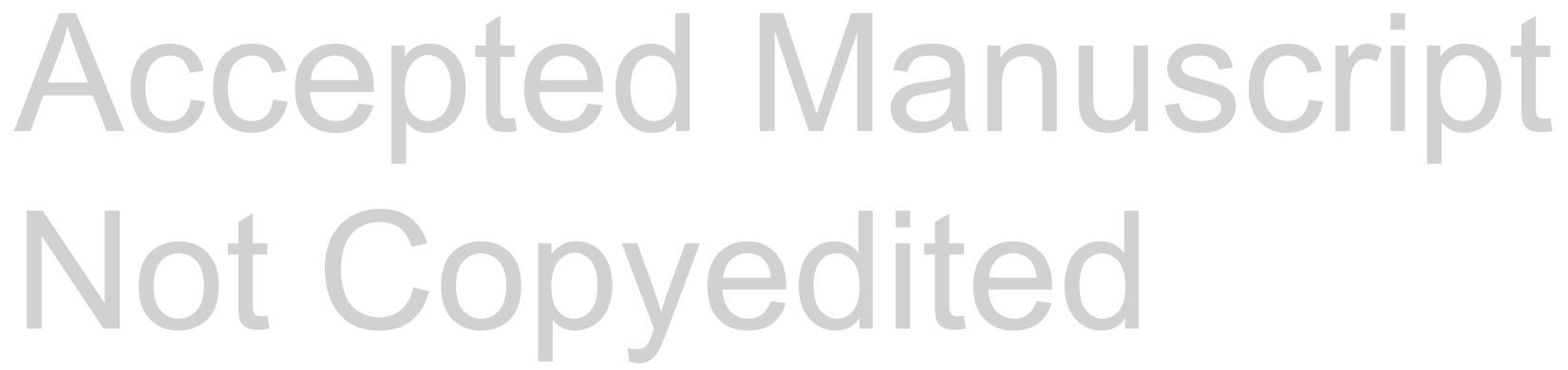


Journal of Composites for Construction. Submitted June 10, 2008; accepted June 11, 2009; posted ahead of print June 22, 2009. doi:10.1061/(ASCE)CC.1943-5614.0000051

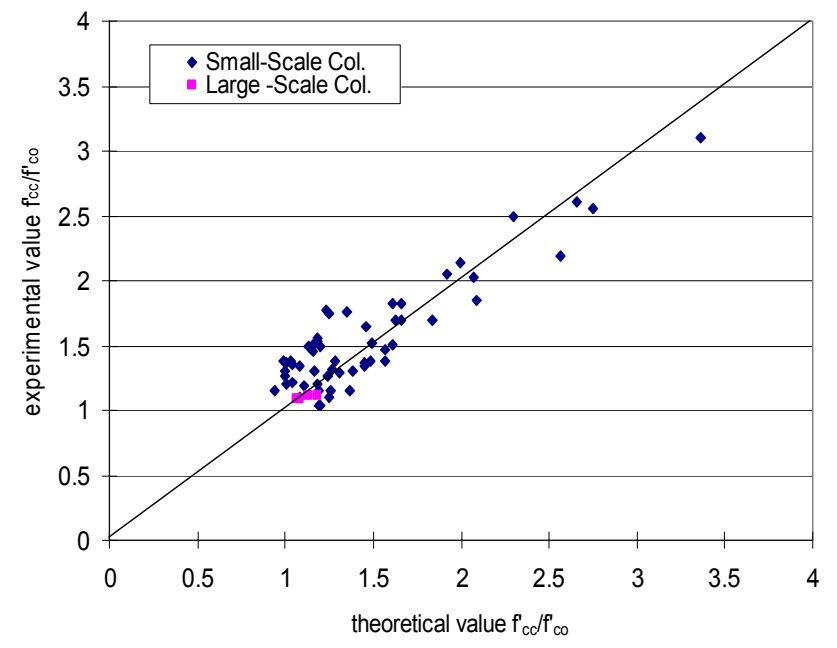

Fig. 9 Performance of newly proposed strength model against 59 data points

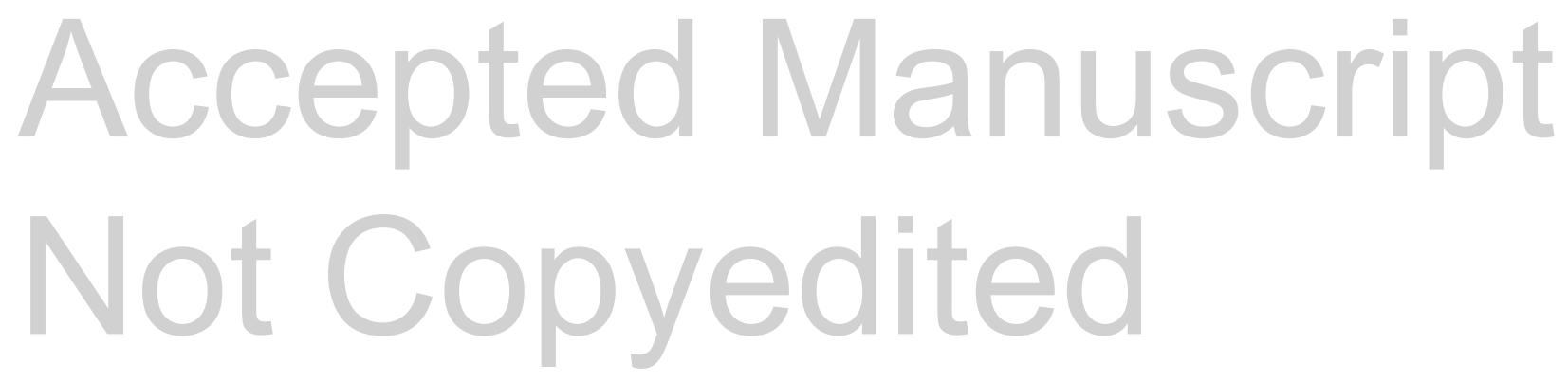

